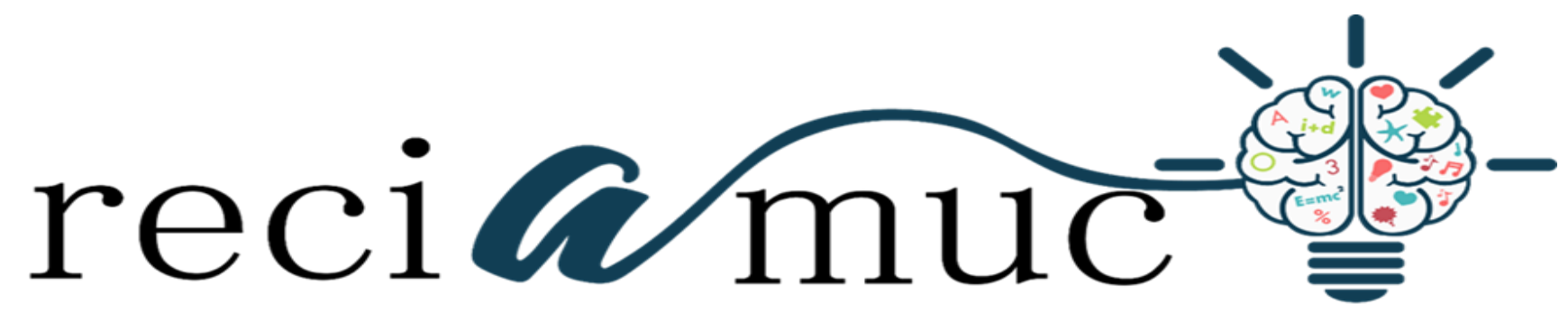

Revista cientifica de investigación actualización del mundo de las ciencias

\begin{tabular}{|c|}
\hline $\begin{array}{l}\text { Cristhian Javier Córdova Molina }{ }^{\mathrm{a}} \text {; Ángel Polibio Moreno Flores }{ }^{\mathrm{b}} \text {; Pedro Rafael } \\
\text { Maruri Orbea }{ }^{\mathrm{c}} \text {; Mario José Criollo Guillen }{ }^{\mathrm{d}}\end{array}$ \\
\hline Las bioimpresora al servicio de los pacientes con quemaduras \\
\hline The bioprinter at the service of patients with burns \\
\hline $\begin{array}{l}\text { Revista Científica de Investigación actualización del mundo de las Ciencias. Vol. } 3 \\
\text { núm., 3, julio, ISSN: 2588-0748, 2019, pp. 107-121 }\end{array}$ \\
\hline DOI: $10.26820 /$ reciamuc/3.(3).julio.2019.107-121 \\
\hline URL: $\underline{\text { http://reciamuc.com/index.php/RECIAMUC/article/view/269 }}$ \\
\hline Código UNESCO: 3205 Medicina Interna \\
\hline Tipo de Investigación: Artículo de Revisión \\
\hline (C) RECIAMUC; Editorial Saberes del Conocimiento, 2019 \\
\hline Publicado: 01/07/2019 \\
\hline Correspondencia: criscordovam@ hotmail.com \\
\hline
\end{tabular}

a. Médico; Investigador Independiente; Guayaquil, Ecuador; criscordovam@hotmail.com

b. Médico; Investigador Independiente; Guayaquil, Ecuador; dranpoli@hotmail.com

c. Médico; Investigador Independiente; Guayaquil, Ecuador; pmaruri@live.com

d. Medico; Investigador Independiente; Guayaquil, Ecuador; mjcg1990@hotmail.com 


\section{Las bioimpresora al servicio de los pacientes con quemaduras}

Vol. 3, núm. 3., (2019)

Cristhian Javier Córdova Molina; Ángel Polibio Moreno Flores; Pedro Rafael Maruri Orbea, Mario José Criollo Guillen

\section{RESUMEN}

Una quemadura es una lesión en los tejidos del cuerpo causada por el calor, sustancias químicas, electricidad, sol, radiación, líquido caliente, vapor, fuego y gases inflamables. La quemadura es el trauma más grave que puede sufrir un ser vivo. El paciente quemado es el modelo más completo y complejo del proceso inflamatorio, donde están presentes todos los mediadores de la inflamación, que llevan a una ruptura del homeostasis, conduciendo a la falla múltiple de órganos. Las quemaduras se clasifican en tres tipos o grados: primero (epidermis), segundo (superficial y /o profunda en la dermis) y tercero (hipodermis). Los tratamientos más novedosos hasta la presente fecha: biomateriales derivados de la sangre (el plasma rico en plaquetas es un derivado sanguíneo concentrado, generado mediante un proceso de centrifugación de la sangre total), Las células madres se destacan por su capacidad de auto regeneración y su replicación asimétrica, en cada división celular una de las células mantiene capacidad de auto regeneración, investigadores en Brasil probaron con éxito usando la piel de un pez de agua dulce de nombre tilapia para curar quemaduras graves (segundo y tercer grado), el tratamiento consiste en sustituir el vendaje y pomada por la piel del tilapia, deja en la zona quemada por varios días. Esto ahorrara costos y también dolor al paciente que ocasiona el cambio de vendaje tradicional. Otras técnicas novedosas: debridación enzimática es una técnica que disuelve el tejido dañado a raíz de la quemadura severa, dejando tejido viable y limpio que favorece la recuperación de la piel sana, reduciendo significativamente los injertos y demás cirugías complejas. La bioimpresora 3D capaz de crear piel humana, $100 \%$ funcional y en un futuro no muy lejano, ser trasplantada a pacientes. Otras ventajas de estos tejidos creados por la bioimpresora, pueden ser empleados para el testeo de productos farmacéuticos, cosméticos y químicos de gran consumo, donde la regulación actual exige el testeo sin animales. La metodología usada es descriptiva, con un enfoque documental, es decir, revisar fuentes disponibles en la red, como google académico, con contenido oportuno, actualizado y relevante desde el punto de vista científico que enriquezca el análisis del tema planteado en este artículo.

Palabras Claves: Quemaduras; Regeneración de Piel; Células Madres; Enzimas; Vendajes Novedosos; Bioimpresión; Plasma Rico en Plaquetas; Tecnología. 


\title{
Las bioimpresora al servicio de los pacientes con quemaduras
}

Vol. 3, núm. 3., (2019)

Cristhian Javier Córdova Molina; Ángel Polibio Moreno Flores; Pedro Rafael Maruri Orbea,

Mario José Criollo Guillen

\begin{abstract}
A burn is an injury to the tissues of the body caused by heat, chemicals, electricity, sun, radiation, hot liquid, steam, fire and flammable gases. The burn is the most serious trauma that a living being can suffer. The burned patient is the most complete and complex model of the inflammatory process, where all mediators of inflammation are present, leading to a rupture of homeostasis, leading to multiple organ failure. Burns are classified into three types or grades: first (epidermis), second (superficial and / or deep in the dermis) and third (hypodermis). The most innovative treatments to date: biomaterials derived from blood (platelet-rich plasma is a concentrated blood derivative, generated by a process of centrifugation of whole blood). Stem cells stand out for their capacity for self-regeneration and its asymmetric replication, in each cell division one of the cells maintains capacity for self-regeneration, researchers in Brazil successfully tested using the skin of a freshwater fish called tilapia to cure severe burns (second and third degree), the treatment consists in replacing the bandage and ointment with the skin of the tilapia, leave in the burned area for several days. This will save costs and also pain to the patient that causes the traditional bandage change. Other innovative techniques: enzymatic debridement is a technique that dissolves damaged tissue following severe burn, leaving viable and clean tissue that favors the recovery of healthy skin, significantly reducing grafts and other complex surgeries. The 3D bio-printer capable of creating human skin, $100 \%$ functional and in the not too distant future, to be transplanted to patients. Other advantages of these tissues created by the bioprinter, can be used for the testing of pharmaceutical, cosmetic and chemical products of great consumption, where the current regulation requires testing without animals. The methodology used is descriptive, with a documentary approach, that is, to review sources available on the web, such as academic google, with timely, updated and relevant content from a scientific point of view that enriches the analysis of the topic raised in this article.
\end{abstract}

Key Words: Burns; Skin Regeneration; Mothers cells; Enzymes; Novel Bandages; Bioprinting; Platelet Rich Plasma; Technology. 


\section{Las bioimpresora al servicio de los pacientes con quemaduras}

Vol. 3, núm. 3., (2019)

Cristhian Javier Córdova Molina; Ángel Polibio Moreno Flores; Pedro Rafael Maruri Orbea, Mario José Criollo Guillen

\section{Introducción.}

Descuidos en el hogar, falta de mantenimiento y seguridad de equipos eléctricos o a gas, manejo imprudente de pirotecnia o del fuego, accidentes con ollas de presión, son algunas de las causas más comunes de quemaduras cuyas marcas o cicatrices dejan huella para siempre en la piel y la vida de un ser humano.

Durante los últimos 50 años, la atención a pacientes quemados ha mejorado significativamente en la supervivencia del paciente posterior a una quemadura. En 1950, un hombre de 25 años de edad con una quemadura del $45 \%$ de su piel tenía una probabilidad de supervivencia del50\% mientras que hoy día, puede sobrevivir con un $80 \%$ de superficie corporal quemada, gracias a los avances de la medicina en este campo(Martínez P. , 2016).

Una quemadura es una lesión en los tejidos del cuerpo causada por el calor, sustancias químicas, electricidad, sol, radiación, líquido caliente, vapor, fuego y gases inflamables. La quemadura es el trauma más grave que puede sufrir un ser vivo. El paciente quemado es el modelo más completo y complejo del proceso inflamatorio, donde están presentes todos los mediadores de la inflamación, que llevan a una ruptura del homeostasis, conduciendo a la falla múltiple de órganos.

Pueden conducir a infecciones porque dañan la barrera protectora de la piel. El tratamiento de las quemaduras está asociado a la causa, profundidad y área del cuerpo afectada. Pomadas con antibióticos son útiles para prevenir y/o tratar infecciones. En quemaduras más severas se requiere limpiar la zona afectada, reemplazar la piel y la ingesta de líquidos y nutrición adecuadas al paciente.

La evolución en el tratamiento de las quemaduras en los últimos años demuestra un claro desafío para los científicos, cirujanos y tecnología actual por disminuir el impacto de la cirugía sobre la lesión, el tiempo de hospitalización, el dolor y las secuelas o cicatrices son un amplio campo por explorar, en el presente artículo se mostrarán a continuación las más actualizadas hasta la fecha de su elaboración. No todas están disponibles en todos los centros de salud debido a su costo y capacitación técnica de los especialistas requerida en estas técnicas novedosas y variadas. No es 


\section{Las bioimpresora al servicio de los pacientes con quemaduras}

Vol. 3, núm. 3., (2019)

Cristhian Javier Córdova Molina; Ángel Polibio Moreno Flores; Pedro Rafael Maruri Orbea, Mario José Criollo Guillen

propósito de esta publicación determinar cuál es la mejor, sino invitar al lector a estar actualizado en los avances a nivel mundial.

\section{Metodología.}

Esta investigación está dirigida al estudio "Las bioimpresoras al servicio de los pacientes con quemaduras". Para realizarlo se usó una metodología descriptiva, con un enfoque documental, es decir, revisar fuentes disponibles en la red, como google académico, con contenido oportuno y relevante desde el punto de vista científico para dar respuesta a lo tratado en el presente artículo y que sirvan de inspiración para realizar otros proyectos. Las fuentes consultadas pueden ser estudiadas al final, en la bibliografía.

\section{Resultados.}

Se define quemadura a la lesión producida en la piel u otro tejido por agentes físicos, químicos o biológicos capaces de generar trastornos que van desde el simple eritema hasta la destrucción total o parcial de los tejidos afectados (Ambrosoni, 2018). Desde una perspectiva fisiopatológico, el paciente quemado presenta un cuadro de hipovolemia secundaria a la extravasación de líquidos al centro intersticial generando caída del gasto cardíaco y oliguria.

Con la reanimación se busca mantener el volumen intravascular y lograr una perfusión tisular adecuada, preservando de esta forma la función orgánica. La reanimación será exitosa cuando se controlen la presión arterial, frecuencia cardiaca y ritmo diurético. El edema se forma transcurrida como máximo en 6 horas, se ve un mejor resultado dentro de las 24 horas, pero su resolución total se alcanza entre 6 -7 días.

Es conveniente realizar un correcto diagnóstico y determinar que especialista médico debe tratarlo(Paredes, 2017):

- La profundidad (tipo de quemadura): se clasifica en atención a la capa de piel y profundidad de la lesión.

- La extensión (superficie corporal quemada total): se determina usando diferentes métodos como regla de los nueve, regla de la palma de la mano y esquema de LundBrowder. 


\section{Las bioimpresora al servicio de los pacientes con quemaduras}

Vol. 3, núm. 3., (2019)

Cristhian Javier Córdova Molina; Ángel Polibio Moreno Flores; Pedro Rafael Maruri Orbea, Mario José Criollo Guillen

- La presencia de lesión por inhalación: el diagnostico se hará por fibrobroncospia, se precisa el tipo de lesión física de la mucosa respiratoria, localización y la intubación orotraqueal precoz antes del desarrollo de un edema. Se usa el algoritmo de Demling en el diagnóstico y manejo.

- La coexistencia de lesiones asociadas.

A continuación, se muestra un cuadro resumen que destaca la clasificación de las quemaduras según su tipo:

Tabla $\mathbf{N}^{\circ}$ 1. Clasificación de las quemaduras

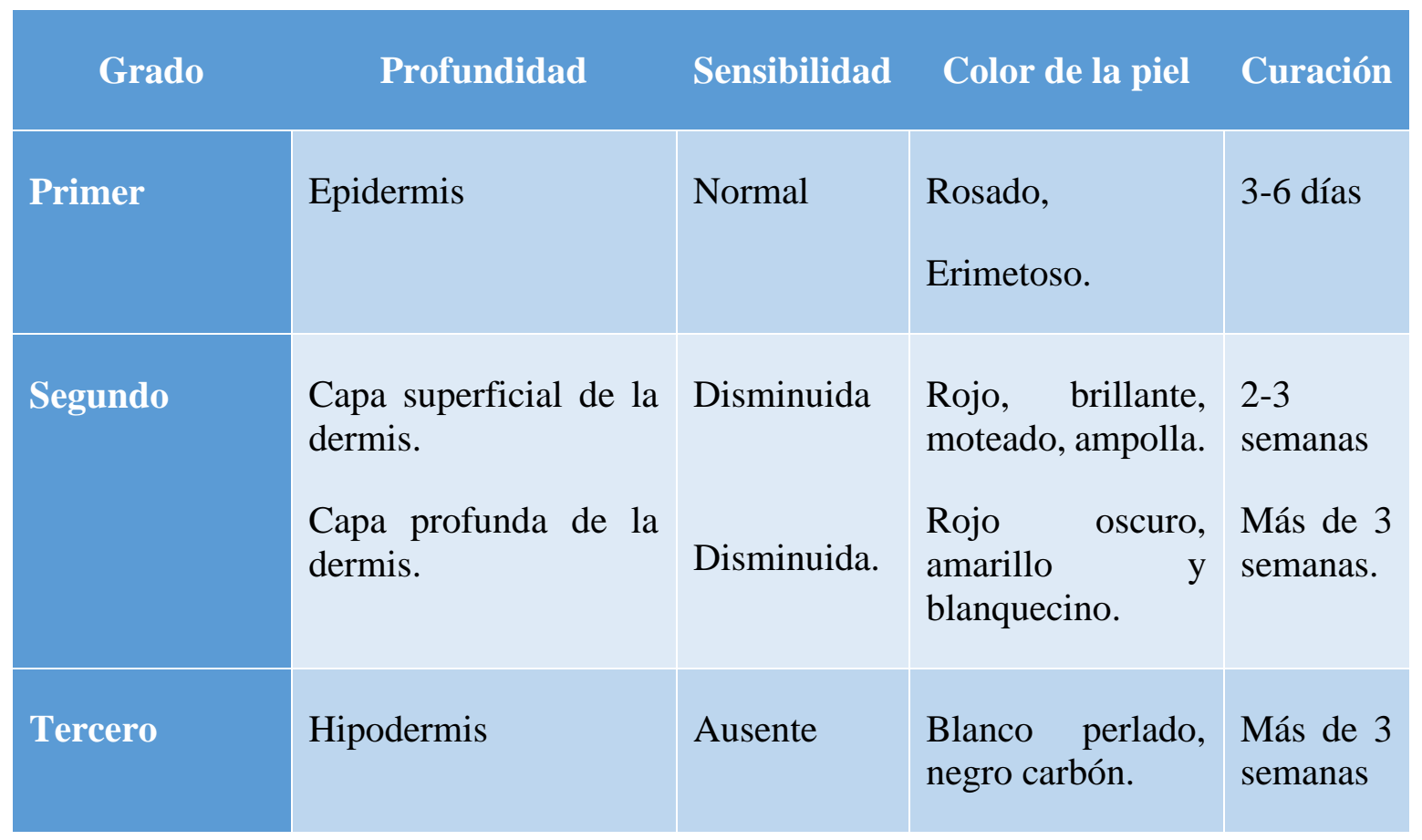

Fuente: Ambrosini (2018)

Un aspecto clave a considerar es el dolor insoportable que padece el paciente quemado, no siempre los analgésicos proveen alivio prolongado. Una toxina derivado del veneno de la tarántula ha mostrado eficacia para paliar el dolor, se espera producir un fármaco de esta toxina en 5 o 10 años (Martínez, 2017). 


\section{Las bioimpresora al servicio de los pacientes con quemaduras}

Vol. 3, núm. 3., (2019)

Cristhian Javier Córdova Molina; Ángel Polibio Moreno Flores; Pedro Rafael Maruri Orbea, Mario José Criollo Guillen

Una de las características de ese dolor además de maleable, es su capacidad de potenciarse. El dolor asociado a las quemaduras no es un dolor de un momento, sino que con el paso del tiempo va en aumento, nótese en el proceso de cura del paciente: quitar la piel muerta, levantar la capa superior de la dermis, cambio diario de vendajes, cuidados para prevenir infecciones y si no es suficiente realizar un proceso de rehabilitación.

El dolor es una interpretación del cerebro, el objetivo de ese estudio es bloquear ese interruptor molecular, si se frena la primera conexión entre nociceptores y médula espinal se inhiba la transmisión de información al cerebro y, por ende, la sensación de dolor. Las posibles patologías del canal de sodio $N a_{v} 1.7$ (gen SCN9A) ya son usadas en la actualidad en algunos fármacos que bloquean específicamente ese canal de sodio y son aptos para consumo humano, permitiendo la pronta elaboración de este fármaco con base a la toxina de tarántula.

\section{Medicina regenerativa en el tratamiento de las quemaduras.}

Biomateriales derivados de la sangre: el plasma rico en plaquetas es un derivado sanguíneo concentrado, generado mediante un proceso de centrifugación de la sangre total que se caracteriza por tener una elevada concentración de plaquetas equivalente a entre $4-6$ veces sus valores normales. La elevada cantidad de factores de crecimiento contenidos en las plaquetas, la capacidad de síntesis de proteínas antiinflamatorias favorece la proliferación celular y síntesis de matriz extracelular, elementos claves en la cicatrización y reparación tisular.

La ventaja de este tratamiento es que el plasma rico en plaquetas es fisiológicamente compatible con los tejidos humanos, los lisados de plaqueta constituyen una alternativa atractiva para sustituir al suero bobino fetal y alcanzar la expansión en el cultivo de las células madre mesénquimalesderivadas de adipocitos.

\section{Terapia celular de las quemaduras.}

Los autotrasplantes de células epiteliales cultivadas y la utilización de células madres mesénquimales entre otras que serán abordadas posteriormente. Las células madres se destacan por su capacidad de auto regeneración y su replicación asimétrica, en cada división celular una de 


\section{Las bioimpresora al servicio de los pacientes con quemaduras}

Vol. 3, núm. 3., (2019)

Cristhian Javier Córdova Molina; Ángel Polibio Moreno Flores; Pedro Rafael Maruri Orbea, Mario José Criollo Guillen

las células mantiene capacidad de auto regeneración, la otra célula entra en un programa de diferenciación e ingresa en una población celular madura que ya no se divide.

La terapia celular consiste en la administración terapéutica de células vivas y conseguir la regeneración celular, el soporte de cualquier defecto funcional como la cicatrización o la modulación de procesos fisiopatológicos como híper inflamación o la disfunción inmune. Los autotrasplantes epidérmicos obtenidos en cultivos representan la primera opción terapéutica para las quemaduras.

Investigadores en Brasil probaron con éxito usando la piel de un pez de agua dulce de nombre tilapia para curar quemaduras graves (segundo y tercer grado). El cirujano plástico Edmar Maciel quien desarrolló el método junto a un equipo interdisciplinario, explica que el tratamiento consiste en sustituir el vendaje y pomada por la piel de la tilapia, deja en la zona quemada por varios días. Esto ahorrara costos y también dolor al paciente que ocasiona el cambio de vendaje tradicional (Maciel, 2017).

La ventaja de usar un animal acuático versus un animal utilizado frecuentemente en estos procedimientos en Europa y EEUU como el cerdo, tiene menos probabilidad de transmitir enfermedades que los animales terrestres. Esta técnica tiene mayor cantidad de proteína (colágeno tipo 1), mejor resistencia (similar a la piel humana) y un grado apropiado de humedad que facilita la cicatrización. Su excelente adherencia evita la contaminación externa, limita la perdida de proteína y plasma que causan deshidratación.

Antes de su uso, la piel del pescado es tratada en un proceso de limpieza: se le quitan las escamas, el tejido muscular, las toxinas y el particular olor a pescado. El segundo paso es estirar la piel en una prensa, cortar en tiras de 10 por $20 \mathrm{~cm}$. El producto es una piel flexible muy parecida a la humana. Finalmente, las tiras se almacenan en un congelador a una temperatura promedio entre $2^{\circ}$ y $4^{\circ}$ por un tiempo máximo de dos años.

Debridación enzimática: es una técnica que disuelve el tejido dañado a raíz de la quemadura severa, dejando tejido viable y limpio que favorece la recuperación de la piel sana, reduciendo significativamente los injertos y demás cirugías complejas. Este concentrado de enzimas 


\section{Las bioimpresora al servicio de los pacientes con quemaduras}

Vol. 3, núm. 3., (2019)

Cristhian Javier Córdova Molina; Ángel Polibio Moreno Flores; Pedro Rafael Maruri Orbea, Mario José Criollo Guillen

enriquecidas con bromelaína obtenida del tallo de la planta ananá viene en presentación de gel de uso tópico, su comercialización fue aprobada en Europa, Argentina y otros países.

Según resultados obtenidos por expertos, esta alternativa terapéutica reduce un $74.7 \%$ el tiempo necesario para eliminar escaras, el tejido muerto en una semana. También disminuye un 65\% de la demanda de cirugías en pacientes quemados, tanto en escarectomías (extracción de tejido), autoinjertos y un $60.9 \%$ el área que requerirá injerto de piel puesto que sólo diluye las células necrosas sin causar daños en tejido sano, reduciendo drásticamente el riesgo a infecciones (Cobos, 2017).

El riesgo a infecciones al cual están expuestas las personas quemadas es mayor que en otra persona porque la piel es la primera barrera contra las infecciones, una bacteria en la zona afectada puede fácilmente trasladarse al torrente sanguíneo y comprometer la quemadura y la vida del paciente. Esta técnica puede reemplazar en algunos casos o ayudar procedimientos quirúrgicos. El desbridamiento enzimático aceleró los tiempos de curación, disminuyendo el soporte analgésico, con curaciones húmedas que facilitan la rehabilitación, disminuye la demanda de transfusiones y costos finales.

Lo fundamental para abordar con éxito a un paciente con quemaduras que llega a emergencias es el diagnóstico oportuno, que establezca el tipo y gravedad, la profundidad de la quemadura y su extensión. La gravedad se asocia a la temperatura y duración frente al agente causante. Se resumen cinco pasos o etapas inmersas en el tratamiento del paciente quemado (Benito, 2004):

1. Salida del shock que produce el hecho, esto demanda entre 48 y 72 horas según el paciente (edad, sexo, nerviosismo etc.,) se suele sedar al paciente o inducirle el coma farmacológico con el propósito de minimizar el dolor. Es fundamental mantener la vía aérea permeable, reponer la pérdida de líquido ocasionada por la quemadura y calmar el dolor. Estabilizado el paciente, el equipo médico lo examina para un diagnóstico más certero.

2. Remoción del tejido necrosado, este procedimiento se realiza con bisturí y ahora puede suplantarse o complementarse dependiendo de la superficie afectada con un procedimiento de Debridación enzimática. 


\section{Las bioimpresora al servicio de los pacientes con quemaduras}

Vol. 3, núm. 3., (2019)

Cristhian Javier Córdova Molina; Ángel Polibio Moreno Flores; Pedro Rafael Maruri Orbea, Mario José Criollo Guillen

3. Reposición cutánea transitoria y definitiva con piel del paciente extraído de sus potenciales zonas donantes. Si la superficie afectada en muy amplia, se hará en varias cirugías. Las impresoras en 3D son muy útiles en este punto o etapa de tratamiento.

4. Tratamientos de las secuelas, tanto funcionales como estéticas, es muy importante la experiencia del cirujano, tecnología disponible, al alcance y paciencia del paciente.

5. Rehabilitación de la mano, (dependiendo de la zona afectada por la quemadura), terapias ocupacionales que se intensificaran en número dependiendo de la condición de salud.

Terapia genética en las quemaduras.

Es una opción terapéutica ideal para acelerar la reparación tisular mediante la utilización de combinaciones de genes (PDGF, IGF-I, KGF, FGF-2) codifican citoquinas o factores de crecimiento para integrar mecanismo biológicos y moleculares de la migración y proliferación celular. Los diversos métodos aportan estos genes a la piel (trasferencia viral). Las células madres adultas son usadas para transportar genes precisos para la reparación tisular (Durango, 2004). A continuación, se explica ese procedimiento adaptado a las quemaduras graves.

Células Madres Adultas: el servicio de cirugía plástica y quemados del Hospital Universitario Valld'Hebronconsiguió tratar exitosamente las cicatrices de varios pacientes producto de quemaduras que afectaron una superficie significativa de su piel mediante la aplicación de técnicas regenerativas de células madres derivadas de tejido adiposo del mismo paciente. Para la obtención del tejido se realizaron pequeñas incisiones para aspirar el tejido adiposo. Se aísla la fracción de células madres adultas y la mesenquimal. En la proporción correcta se inyectan al paciente dentro de las cicatrices y tejido blando.

Las células madres mesenquimiales crean un microambiente en el tejido que estimula la creación de nuevos vasos, secreta factores de crecimiento y promueve la creación de nuevas estructuras moleculares, aumentado el colágeno y demás elementos elásticos, dando una apariencia más favorable, parecida a tejidos normales. El objetivo de este tratamiento consiste en mejorar las características físicas de las cicatrices para poder aumentar su elasticidad, flexibilidad, mejorar las secuelas y aumentar el estado de vitalidad de estos tejidos (Gaceta Médica, 2014). 


\section{Las bioimpresora al servicio de los pacientes con quemaduras}

Vol. 3, núm. 3., (2019)

Cristhian Javier Córdova Molina; Ángel Polibio Moreno Flores; Pedro Rafael Maruri Orbea, Mario José Criollo Guillen

Algunos beneficios aportados por este tratamiento:

- Se puede tratar cualquier atrofia en los tejidos blandos.

- Los primeros resultados son visibles en unos meses.

- Se realiza un tratamiento biológico de las quemaduras.

- Es un tratamiento regenerativo en contrate a las técnicas quirúrgicas.

- Se minimiza el daño de la misma cirugía (no crea nuevas cicatrices).

Bioimpresoras $3 D$.

Un equipo de científicos españoles ha diseñado un prototipo de bioimpresora $3 D$ capaz de crear piel humana, $100 \%$ funcional y en un futuro no muy lejano, ser trasplantada a pacientes. Inicialmente, a comienzos de 2000 se diseñó un sistema "in vitro", a partir de pequeñas biopsias de un paciente se puede generar toda su piel en tres semanas, tratamiento ampliamente usado en unidades de quemados en muchos hospitales de España (Nature Biotechnology, 2016).

Los objetivos por alcanzar están: la automatización del proceso, producción a mayor escala y abaratar los costes de la creación de piel humana. Esta técnica se encuentra en fase de aprobación por parte de los diferentes entes regulatorios europeos, quienes deben garantizar que la piel producida sea apta para su utilización en trasplante a pacientes con quemaduras y otros problemas de piel. Otras ventajas de estos tejidos, pueden ser empleados para el testeo de productos farmacéuticos, cosméticos y químicos de gran consumo, donde la regulación actual exige el testeo sin animales.

La bioimpresora hace una réplica de la estructura natural de la piel, con una primera capa externa, (la epidermis) con su estrato córneo que protege contra el medio ambiente exterior, junto a otra más profunda y gruesa, la dermis. La última capa está integrada por fibroblastos (producen colágeno), la proteína que le da elasticidad y resistencia mecánica.

Se utilizan biotintas y no cartuchos con tintas de colores. Las jeringas empleadas con diferentes componentes biológicos: células, proteínas, factores de crecimiento y andamiajes (estructuras en las que se integran las proteínas para dar forma al tejido). Los componentes son los mismos que 


\section{Las bioimpresora al servicio de los pacientes con quemaduras}

Vol. 3, núm. 3., (2019)

Cristhian Javier Córdova Molina; Ángel Polibio Moreno Flores; Pedro Rafael Maruri Orbea, Mario José Criollo Guillen

los usados en la creación de piel a mano, adaptados a la impresora, con tres módulos: ordenador, los depósitos de las biotintas y el módulo de impresión.

La deposición de las biotintas está controlada por el ordenador y se realiza en forma ordenada en una placa para ir produciendo la piel, luego se introduce en una incubadora a 37 grados centígrados.El proceso de producción de estos tejidos se puede realizar de dos maneras:

- Piel autóloga, creada caso a caso a partir de células del propio paciente para usos terapéuticos como quemaduras graves.

- Piel alogénica, a partir de células de cualquier persona donante.

La piel alogénica es la más indicada para testar químicos, cosméticos o medicamentos. Independientemente del proceso que se escoja, hay que extraer las células del paciente/donante a través de una pequeña biopsia, cultivarlas en el laboratorio y conseguir su multiplicación, en un proceso que puede durar de dos a tres semanas. Conseguido un número suficiente de células, se mezclan con el resto de componentes biológicos para la impresión, que tomará aproximadamente unos pocos minutos.

La impresora trabaja en condiciones de seguridad biológica para evitar contaminación de otros agentes, por ejemplo, bacterias. Los cartuchos cargados de células junto con un programa informático, la impresora puede imprimir un tejido vivo sobre un material sintético, produciendo una piel artificial con calidad superior a la piel cultivada. Otra ventaja es que la técnica de la bioimpresión permitirá reducir el tiempo de curación del paciente. El mayor reto a futuro es reproducir tejidos más complejos como vasos sanguíneos o folículos pilosos(Ramudo, 2017).

\section{Conclusión.}

Los accidentes son parte de la cotidianidad, cuyo número ha disminuido en el tiempo, especialmente los relacionados a quemaduras. Un aspecto clave a considerar es el dolor insoportable que padece el paciente quemado, no siempre los analgésicos proveen alivio prolongado. Una de las características de ese dolor es su capacidad de potenciarse. El dolor asociado a las quemaduras no es un dolor de un momento, sino que con el paso del tiempo va en aumento, nótese en el proceso de cura del paciente: quitar la piel muerta, levantar la capa superior 


\section{Las bioimpresora al servicio de los pacientes con quemaduras}

Vol. 3, núm. 3., (2019)

Cristhian Javier Córdova Molina; Ángel Polibio Moreno Flores; Pedro Rafael Maruri Orbea, Mario José Criollo Guillen

de la dermis, cambio diario de vendajes, cuidados para prevenir infecciones y si no es suficiente realizar un proceso de rehabilitación.

Esta realidad ha inspirado a muchos científicos en el mundo en la búsqueda de mejores tratamientos que alivien no solo el dolor del paciente, sino que también mejoren el aspecto estético de las quemaduras y cicatrices de las intervenciones quirúrgicas, mejorando el coste del tratamiento en algunos casos y la calidad de vida del paciente. Los tratamientos descritos en este artículo se clasificaron en tres categorías para pacientes quemados:

Medicina regenerativa: el plasma rico en plaquetas es un derivado sanguíneo concentrado, generado mediante un proceso de centrifugación de la sangre total, la elevada cantidad de factores de crecimiento contenidos en las plaquetas, la capacidad de síntesis de proteínas antiinflamatorias favorece la proliferación celular y síntesis de matriz extracelular, elementos claves en la cicatrización y reparación tisular. La ventaja de este tratamiento es que el plasma rico en plaquetas es fisiológicamente compatible con los tejidos humanos.

Terapia celular: investigadores en Brasil probaron con éxito usando la piel de un pez de agua dulce de nombre tilapia para curar quemaduras graves (segundo y tercer grado). El cirujano plástico Edmar Maciel quien desarrolló el método junto a un equipo interdisciplinario, explica que el tratamiento consiste en sustituir el vendaje y pomada por la piel de la tilapia, deja en la zona quemada por varios días. Esto ahorrará costos y también dolor al paciente comparado con el vendaje tradicional. Esta técnica tiene mayor cantidad de proteína (colágeno tipo 1), mejor resistencia (similar a la piel humana) y un grado apropiado de humedad que facilita la cicatrización. Su excelente adherencia evita la contaminación externa, limita la perdida de proteína y plasma que causan deshidratación.

Terapia genética: las células madres mesenquimiales crean un microambiente en el tejido que estimula la creación de nuevos vasos, secreta factores de crecimiento y promueve la creación de nuevas estructuras moleculares, aumentado el colágeno y demás elementos elásticos, dando una apariencia más favorable, parecida a tejidos normales. La bioimpresora 3D hace una réplica de la estructura natural de la piel, con una primera capa externa, (la epidermis) con su estrato córneo 


\section{Las bioimpresora al servicio de los pacientes con quemaduras}

Vol. 3, núm. 3., (2019)

Cristhian Javier Córdova Molina; Ángel Polibio Moreno Flores; Pedro Rafael Maruri Orbea, Mario José Criollo Guillen

que protege contra el medio ambiente exterior, junto a otra más profunda y gruesa, la dermis. La última capa está integrada por fibroblastos (producen colágeno), la proteína que le da elasticidad y resistencia mecánica.

Se utilizan biotintas y no cartuchos con tintas de colores. Las jeringas empleadas con diferentes componentes biológicos: células, proteínas, factores de crecimiento y andamiajes (estructuras en las que se integran las proteínas para dar forma al tejido). Los componentes son los mismos que los usados en la creación de piel a mano, adaptados a la impresora, con tres módulos: ordenador, los depósitos de las biotintas y el módulo de impresión.

Existe una amplia gama disponible de tratamientos en la actualidad, la selección del mismo dependerá de la disponibilidad y su coste.

\section{Bibliografía.}

Ambrosoni, M. (2018). Propuesta de tratamiento del gran quemado en la unidad de cuidados intensivos. Archivo de Pediatria del Uruguay, 129-134 www.scielo.edu.uy.

Benito, E. D. (21 de Enero de 2004). Un nuevo métodoregenera toda la piel a partir de un trozo como un sello. Obtenido de El Pais.: www.elpais,com

Cobos, M. (Octubre de 2017). Lo último en el tratamiento de quemaduras graves. Obtenido de La Prensa Argentina: www.laprensa.com.ar

Durango, L. (Marzo de 2004). Manejo médico del paciente quemado. Revista IATREIA Volumen $17 N^{\circ} 1$, www. Obtenido de www

Gaceta Médica. (14 de Julio de 2014). Inyectan células madres para la regeneración de las quemaduras. Obtenido de Gaceta Medica Madrid: www.GacetaMedica.com

Maciel, E. (10 de Enero de 2017). Revolucionario método desarrollado en Brasil para tratar quemaduras graves con piel de pez. Obtenido de BBC NEWS: www.t13.cl 


\section{Las bioimpresora al servicio de los pacientes con quemaduras}

Vol. 3, núm. 3., (2019)

Cristhian Javier Córdova Molina; Ángel Polibio Moreno Flores; Pedro Rafael Maruri Orbea, Mario José Criollo Guillen

Martínez, L. (29 de Diciembre de 2017). Quemaduras, cada vez más cerca de un tratamiento eficaz contra el dolor. Obtenido de EFE Salud: www.efesalud.com

Martínez, P. (24 de Julio de 2016). BAI una app que clacula la superficie corporal quemada en $3 D$. Obtenido de El Referente: www.elreferente.es

Nature Biotechnology. (16 de Febrero de 2016). Las bioimpresoras 3D ya crean tejidos vivos que se pueden trasplantar. Obtenido de OKDIARIO: www.okdiario.com

Paredes, S. (2017). Quemaduras. Manejo inicial y tratamiento. Obtenido de www.colmedsa.com.ar

Ramudo, M. (17 de Septiembre de 2017). Bioimpresoras y células madres para tratar pacientes quemados. Diario Médico, pág. www.Comunicacion.com.

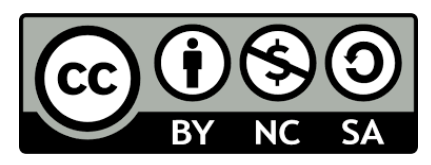

RECONOCIMIENTO-NOCOMERCIAL-COMPARTIRIGUAL

CC BY-NC-SA

ESTA LICENCIA PERMITE A OTROS ENTREMEZCLAR, AJUSTAR Y CONSTRUIR A PARTIR DE SU OBRA CON FINES NO COMERCIALES, SIEMPRE Y CUANDO LE RECONOZCAN LA AUTORÍA Y SUS NUEVAS CREACIONES ESTÉN BAJO UNA LICENCIA CON LOS MISMOS TÉRMINOS. 